\title{
A Survey Study- Incidence of Renal Failure In Pediatric Patients Secondary To Ayurvedic Drug Consumption.
}

\author{
${ }^{1}$ Dr. Pashte Vidya Uddhavrao , ${ }^{2}$ Dr. Kale A. B. ${ }^{3}$ Dr. Swamy T.Y., ${ }^{4}$ Dr. Rana A. P. \\ ${ }^{1}$ PG 2nd Pediatric Dept. Government Ayurved Hospital Osmanabad \\ ${ }^{2}$ HOD \& Professor Pediatric Dept. Government Ayurved Hospital Osmanabad \\ ${ }^{3}$ Professor Pediatric Dept. Government Ayurved Hospital Osmanabad \\ ${ }^{4}$ Assistant Professor Pediatric Dept. Government Ayurved Hospital Osmanabad
}

\begin{abstract}
-
A 13 question survey was conducted by visiting 15 Nephrologists (cities around Osmanabad district), regarding incidence of renal failure due to Ayurvedic drug consumption in children.10 surveys were responded (66\%). The purpose of the survey was to determine any history of Ayurvedic drug before children land into renal failure, a direct correlation between renal failure and use of Ayurvedic drugs. Nephrologist were also questioned about renal pediatric patients. Survey results showed that out of 10 Nephrologist, $3(30 \%)$ of them told about data having h/o Ayurvedic drugs before admission of patient in their hospital \& about 7 Nephrologist (70\%) claimed about no such history \& some of them told about even no single case has been seen in their 15-25-year practice.
\end{abstract}

Keywords - Renal failure, Pediatric, Ayurvedic drugs, Survey.

\section{Introduction -}

Our purpose for this survey study was to see the incidence of renal failure in pediatric patients due to ayurvedic drug consumption. As rasaushadhi are used by our Balroga department of Govt.Ayurved Hospital Osmanabad \& patients got relief from their illness; as we expected, in spite of this adverse effects of rasaushadhi remain questionable.

Rasaushadhi (medicines containing metals-nonmetals along with herbal drugs) are judiciously used by many Ayurvedic pediatric practitioners \& non medico peoples also. In Ayurveda use of these drugs is only indicated after proper processing like shodhan, maran, amrutikaran etc. There are so many hazards due to improper use of medicines including Ayurvedic drugs. As pediatric dosing system is different from adults, improper use of drugs may affect the children's \& they might be faced by many life threatening complications. Side effects of any medicine often seen due to improper processing of drug, wrong indication, incorrect dose or due to prescribed by nonmedico peoples. Due to these conditions many hazards are seen and patient may land into renal failure $\&$ by this way entire system is being blamed.

We surveyed 10 Nephrologist practicing around Osmanabad District in 24 March 2018-5 May 2018 (interview based survey). This paper describes the result of a survey of Nephrologist around Osmanabad District. The purpose was to determine no of pediatric patients having h/o ayurvedic drug consumption before landing into renal failure. Accordingly, we here report the results of a survey targeting nephrologists with 13 questions regarding incidence of renal failure pediatric patients secondary to ayurvedic drug consumption.

\section{Materials \& methods -}

A 13-question interview based survey was conducted by previous phone contact with Nephrologist for permission for direct visit for survey study (contacts received from internet/website). After phone contacts, 
${ }^{1}$ Dr. Pashte Vidya Uddhavrao, International Journal of Ayurvedic \& Herbal Medicine 8(4) July.-August. 2018 (3007-3009)

we received visit date $\&$ then we visited to Nephrologist accordingly. The main method of analysis was to compare responses about the past $\mathrm{h} / \mathrm{o}$ ayurvedic drugs in pediatric renal failure patients recorded by Nephrologist in their long term practice.

The questions are listed in following table-1

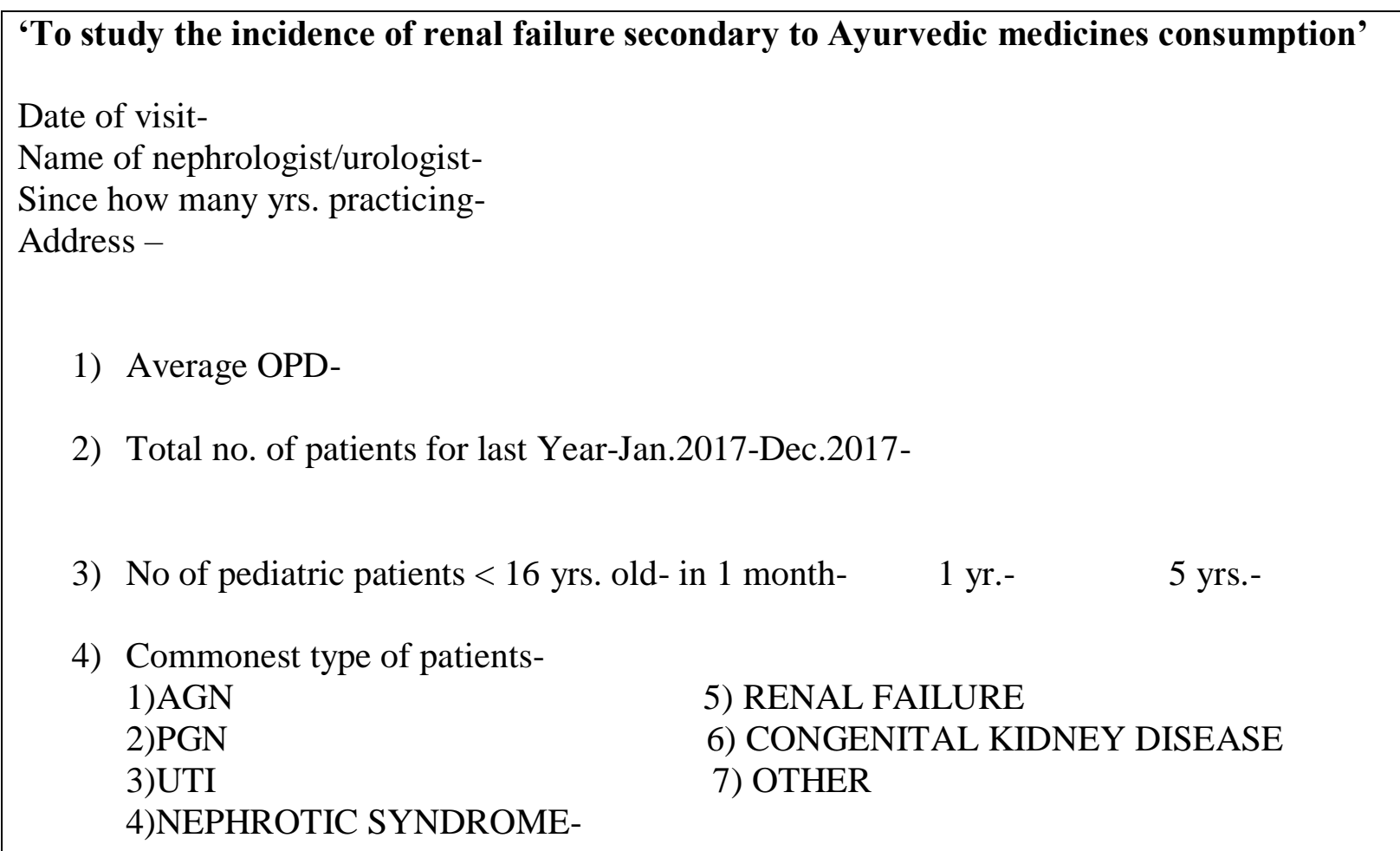

5) Whether renal failure- Acute/Chronic Are recorded for cause?

6) What are common etiological factors-

7) Whether patients give the history of taking any ayurvedic drug?

8) How many such cases are recorded for last 1 month- $\quad 1 \mathrm{yr}-\quad 5 y r s-$

9) Whether drug prescription is available?

For what purpose patient received medication?

10) If prescription is available, whether qualified Dr., Physician, Pediatrician-

11) Whether any Pediatrician prescribe? -

For what-

11) How many drugs? -

13) Which medicines?-

\section{Results -}

No of Nephrologist- 10

4- reported no any past h/o ayurvedic drugs (around 15-20 general pediatric pts/month). 
3- reported 1-2 pts/20/month

1-reported 4-5 pts/10/month

1 -reported $10 \mathrm{pts} / 30 / \mathrm{month}$

1-reported 10-15/50-60/month

past h/o ayurvedic medicines.

Out of 6,3 reported h/o renal failure due to ayurvedic drug (1-2\% pts).

3 out of 10 Nephrologist (30\%) reported case of renal failure 1-2\% pediatric pts due to ayurvedic drug consumption. But they don't have prescriptions and duration of drug used, on their experience based observation they claimed. Remaining 7 Nephrologist reported even no single case of pediatric renal failure pts due to ayurvedic drugs is seen in their 10-25-year practicing period.

\section{Discussion -}

Experience based information collected by Nephrologists \& results are compared accordingly. As described in results, 3 (30\%) Nephrologist told about positive relation between renal failure and use of ayurvedic drug in pediatric pts (1-2\%), only based on their observation and not having any proof. About 7 Nephrologist reported that they don't have seen any data about these criteria.

Comparative survey results are summarized in table-2

\begin{tabular}{|l|l|l|l|l|l|}
\hline $\begin{array}{l}\text { No of } \\
\text { Nephrologist }\end{array}$ & $\begin{array}{l}\text { How many } \\
\text { years practicing }\end{array}$ & $\begin{array}{l}\text { Pediatric } \\
\text { OPD/month }\end{array}$ & $\begin{array}{l}\text { Pediatric pts } \\
\text { reported with renal } \\
\text { failure/month }\end{array}$ & $\begin{array}{l}\text { h/o } \\
\text { ayurvedic } \\
\text { drugs }\end{array}$ & $\begin{array}{l}\text { h/o renal failure } \\
\text { due to ayurvedic } \\
\text { drugs }\end{array}$ \\
\hline 1. & 25 & 10 & 2 & 0 & 0 \\
\hline 2. & 10 & $5-6$ & 1 & 0 & 0 \\
\hline 3. & 15 & 20 & 1 & $1-2$ & 0 \\
\hline 4. & 5 & 10 & $1-2$ & $4-5$ & 0 \\
\hline 5. & 7 & 30 & $1-2$ & 10 & 1 \\
\hline 6. & 20 & 5 & $0-1$ & $1-2$ & 0 \\
\hline 7. & 10 & $50-60$ & $2-3$ & $10-15$ & $1-2$ \\
\hline 8. & 24 & 10 & $0-1$ & $1-2$ & 1 \\
\hline 9. & 26 & 10 & $1-2$ & 0 & 0 \\
\hline 10. & 20 & 10 & $0-1$ & 0 & 0 \\
\hline
\end{tabular}

\section{Conclusion -}

Proper use of ayurvedic medicine in pediatric practices is safe and there is no relation with renal failure when used properly. 1-2 cases found in this survey study but they don't have proper history and no availability of prescriptions.

\section{Limitations of the study-}

The study limitations are low response rate. The low response rate could be due to variety of reasons, but in future studies further follow up could be of some benefit to obtain more responses. 